To be cited as: Dovey, K. \& Wood, S. (2015)

'Public/Private Urban Interfaces'

Journal of Urbanism, 8 (1): 1-16

\title{
PUBLIC/PRIVATE URBAN INTERFACES: Type, Adaptation, Assemblage
}

\author{
Kim Dovey and Stephen Wood
}

\begin{abstract}
The urban interface between private and public space, the ways in which private plots plug into public networks, has long been recognized as a key issue in urban design theory. This paper presents a typology for the mapping and analysis of public/private interfaces. Drawing on mappings of the mixed morphology of the Australian inner-city, we develop a simple typology of five primary interface types classified according to access, setback, transparency and mode of access. From a theoretical framework of assemblage theory, the interface is construed as a socio-spatial assemblage wherein types are diagrams of connectivity that enable the creation, production and reproduction of ideas, goods, services and identities. In the second part of the paper we explore the complex dynamics of adaptation and transformation from one type to another. The paper raises questions about the methodology and ontology of micro-spatial analysis in urban research, as well as the importance of interface connections to urban production, exchange and innovation.
\end{abstract}

\section{INTRODUCTION}

The urban interface between public and private space has long been an issue of great concern in urban design, planning and architectural theory - the myriad of ways in which the transition from public to private space is framed, formed, negotiated and governed. It has been of particular concern to social critiques of built form because this is a primary site of transition from private to public selves and vice versa; where friends and customers are greeted and farewelled; where identities are constructed (the entry foyer, front door, front garden); where goods are displayed and exchanged (shop window); where social activity occurs in interstitial space (front porch, alfresco dining); where safety is established both with boundaries and passive surveillance. Some functions are strongly identified with particular types of public/private interface. The public shopping strip is largely a repetition of transparent shopfronts, just as the suburb is a repetition of garden setbacks. Other parts of the city are not so uniform nor easily categorised and the issue has become more complex through the proliferation of quasi-private space within private shopping malls, housing estates and so on.

The broad research question here concerns the relationship of the private building plot to the street how does private space plug into public pedestrian networks? The first goal is to develop an interface typology that may be useful for mapping, analyzing and controlling public/private interfaces. Second, we seek to understand practices of innovation, adaptation and transformation from one interface type to another. In order to do both of these we deploy forms of thinking that resonate with early attempts to articulate these issues such as Jacobs, Alexander and Lynch and with assemblage theories of Deleuze and Guattari (1987). The broader goal is to enable a more rigorous and robust discourse on interfaces to emerge in both theory and practice.

Our database for the development of this typology emerged from a study of creative clusters in the inner-city of three Australian cities (Sydney, Brisbane and Melbourne) incorporating a diversity of building types, functions and densities, producing a broad range of interface types. The ways in which buildings and businesses are plugged into public space emerged as a highly salient issue both in this study and in earlier studies of urban character and place identity (Author). In places with high levels of consistency the interface is scarcely worth mapping but our interest here was piqued in part by the complexities of mapping and slippages between categories. We have long regarded mapping as much more than simply documenting data; maps are a means to an understanding of how cities work and 
generating new ways of thinking about them (Corner 1999). The multi-layered database becomes a research tool for investigating relations between layers. While the public/private interface of a modern suburb is generally consistent and enforced by planning codes, in the inner city locations we are studying they are thoroughly mixed. There is no standard typology nor agreed method for categorizing or mapping such interface morphologies, and we found that most category systems we developed tended to become unstable. The more difficulty we found in mapping interfaces the more interesting the problem became, because the slippages between types became relevant to the innovative practices that are the main subject of the project. In other words the hypothesis emerged that the rich mix of interface types and the slippages between them are linked to urban innovation. Our concern in this paper is with the interface typology; the ways in which this may or may not be geared to creative clusters is the subject of further work.

The public/private interface has long been regarded as a key dimension of urban design, central to commercial and social exchange, and reflected in slogans such as 'eyes on the street' and 'active edges' (Jacobs 1961). Alexander's well known Pattern Language stressed the crucial role of the edge of public space (Alexander et al 1977). The social importance of the interface was established early in the field of environmental psychology. For Goffman (1959) it is the site where back region becomes front region, where identities are performed in everyday life. For Altman (1975) privacy is essentially a dialectic between private and public where control over access to others depends on socio-spatial boundary controls - the interface mediates power relations. Interfaces resonate with the ambivalence Simmel $(1978,1950)$ associates with the simultaneous desires to engage with and retreat from an urban life of strangers. For Simmel (1997) the public doorway "demonstrates in decisive fashion how separating and connecting are only two faces of one and the same action." The interface is a key means by which individuals negotiate the ineluctable presence in urban milieus of people who are "socially distant yet physically close" (Bauman 1993: 153). Like the double-faced Janus, Roman god of doors and gates, the interface is essentially double, separating and connecting levels of a socio-spatial hierarchy - part/whole, individual/collective, self/society. The interface is where we both welcome and exclude strangers (Iveson 2006); where we negotiate both 'publicity' and 'privacy', exposure to the public gaze and retreat from it.

The study of public/private interfaces is one way to a more rigorous understanding of the concept of urban 'porosity' as introduced by Benjamin and Lacis in their 1924 description of the tenement slums of Naples (Benjamin 1996). Porosity has become a much used and abused term in urban design discourse sometimes a synonym for network permeability, other times referring to buildings with lots of holes in them. In the original essay porosity involved the transgression of social, spatial and temporal boundaries with a focus on the ways that spaces of domesticity and production interpenetrated and blurred with urban public space producing an intensity of public life and the street as a 'theatre' - an earlier precursor to Jacobs' (1961) notion of the interface as 'place ballet'. Linked to adaptation and a provisional quality of everyday urban life, 'porosity results above all from the passion for improvisation' (Benjamin 1996: 168). These observations were linked to the Neapolitan morphology of cafes, workshops, balconies and entry courts under conditions of high density and poverty but they remain relevant today. Part of the promise in understanding interfaces is that we get closer to understanding the potential of thresholds as places of becoming and transformation.

The public-private interface was a key focus for Newman's (1972) critique of the emergence of a no man's land between the street and front door under modernist planning. While Newman did not develop a detailed interface typology, his prognosis was effectively for the eradication of one particular type (the ambiguous, semi-private setback) and a reinforcement of defensible boundaries. In his discussion of 'control' in public space Lynch (1981) distinguishes between rights of presence, use, appropriation, modification and disposition - while such rights often focus on interfaces this is a typology of rights rather than interfaces. Much of this early theory has been popularized through phrases such as 'mixed use', 'active edges' and 'eyes on the street' (Bentley et al 1985) and the importance of the public/private interface has remained current in most mainstream urban design theory (Madanipour, 2003; Carmona et al 2003). We are also seeing the emergence of complex typologies of public space (Carmona 2010) wherein the interface is a subset. There have been many critiques of the privatization of public space and somewhat apocalyptic claims about the 'end of public space' (Sorkin 1992), yet these new quasi-public realms of shopping mall, themepark and gated community have their own interfaces with the public city that need to be better theorized. 
With all of this attention on the interface over 50 years it is surprizing to find only three typologies that form precedents for this study. Gehl has long classified such interfaces along a continuum of 'soft' (social, permeable, active) versus 'hard' (anti-social, impermeable, dead) based on social attraction (Gehl 1987, Gehl \& Gemzoe 1996). He incorporates such factors as speed (pedestrian versus car), transparency, activity, diversity, design quality and grain-size to produce a 5-part façade typology that ranges from A (active, small-grain, good details) to E (passive, large-grain, no details) (Gehl et al, 2006). This typology is design-driven and geared primarily to attractiveness and social outcomes such as streetlife vitality and safety; constructed in order to diagnose and eliminate blank, passive, anti-social facades. While many such linkages of built form to streetlife are well-established (Mehta 2007; Ford 2000), we seek a more fine-grained typology and our questions are more descriptive than normative. Habraken (1998) has developed a multi-scalar typology of gateways, entrances or portals at all scales from the room to the nation based on the ways they mediate flows between different kinds of social and legal territories. The primary variables are whether such entrances connect inside to outside (as in a building entrance) and whether they connect different levels of a spatial hierarchy (as in a private/public interface). This is a useful typology that encompasses flows of people across all kinds of boundary but public/private interfaces comprise only a small part of it. Bobic (2004) develops the most detailed of entrance typologies with seven primary types and forty subtypes based on criteria such as setback, transparency, behavior and design quality. While the subtypes are relatively clear, they are impossibly complex and would be impossible to map. The seven primary types are neither robust nor clear. This typology is also problematic for our purposes because it is an entrance typology that excludes all impermeable interfaces.

While this is not the place to review typomorphological approaches to urban studies (Moudon 1994) we would like to clarify the ways we use the term 'type'. We share with such traditions the idea of type as a pattern of repetition of formal configurations incorporating a deeper connection to social and economic functions, while resisting any reduction to either form or function. This is distinct from the ideal types of the so-called 'rationalists' of urban design theory such as Rossi or Krier - there is no transcendent idea that is being copied. Types are not objects, in our case they are typical forms of connectivity, typical connections of private plots to public networks. Our more theoretical concern is not only to map the range of possible interface types, but also to understand what capacities different types have to affect and to be affected by different circuits of social and economic exchange. How do the formal logics embodied in different interface types become entangled in other social and economic logics? Entrance transitions, setbacks, levels of privacy and transparency are geared to practices of economic exchange, social reproduction and transport technologies. The interfaces that characterize shopping strips, suburban streets and factory walls are not randomly produced. In this sense interfaces are not 'things' but connections, relations and flows that are geared to productive practices. Our initial question is not 'how should they be designed?' but 'how do they work?'. Such a view resonates with assemblage theory - a term used to designate the ways that productive self-organised wholes emerge from dynamic interactions between parts including people and things, subjects and objects (Deleuze \& Guattari 1987; DeLanda 2006; McFarlane 2011, Author 2011). As a verb assemblage focuses attention on processes of connecting - connecting people or firms to each other, producers to consumers, people to buildings, public to private space. As a noun the assemblage is a cluster of interconnections rather than a 'thing'. It is akin to a 'place' in the sense that it is a socio-spatial territory with some form of identity, however fluid (Author 2010: Ch.2). Assemblage is fundamentally dynamic and productive, a dynamism based primarily in horizontal networks of connectivity (pedestrian networks) yet also stabilised by hierarchical structures (policies, planning codes, laws). Assemblage theory cuts across any separation of subject and object; it is fundamentally socio-spatial with the spatial and social parts mutually constituting each other. Like the term 'place' assemblage is multi-scalar - assemblages at scales of building, street,

neighbourhood, city and globe are interconnected and analysis at a single scale can be inherently blind. Yet assemblage thinking opposes the idea that the large scale is more important than the small, or that local conditions can be reduced to higher level controls. Agency and power flow not only top down but are distributed across networks. Actor network theory (Latour 1987; Farias \& Bender 2010) can be construed as a variety of assemblage thinking where agency is distributed across the non-human spatial and material world. Thick empirical description and micro-scale urban analysis become important to reveal the ways assemblage works. Assemblage theory is emerging as an important form of critical urbanism with key links to urban political economy (McFarlane 2011). To study only the larger 
assemblage of the city or neighbourhood and its planning framework is to ignore the ways that conceptions of place, urban character and creative clustering are emergent effects of a multitude of small-scale adaptations. This study of the ways buildings interface with public street networks focuses on the intersection of two levels of assemblage - the architectural and the urban. This incorporates the ways in which various agents_-people, families, firms, shops_interface with their neighbourhood.

\section{URBAN INTERFACE TYPES}

While in social terms the meanings of 'public' and 'private' space are ultimately contestable, our focus is on the materiality of the interface along the legal cadastral boundary. We suggest that the following variables are primary in understanding this interface:

Accessible/Inaccessible: This variable describes the degree to which the public/private interface is permeable or porous as a pedestrian entry to private property. Access establishes the interface activity or lack thereof; it enables pedestrian flow across the interface. This is the zero-degree variable that defines the interface as an entrance or not. Where there is no portal through which to pass, no door on which to knock, nor bell to press, there is a form of social blankness. Such blank interfaces have long been derided in urban design theory as those that lack vitality, identity and safety, although they do have other capacities.

Direct/Setback: Is the primary entry into private space directly on the legal boundary or setback from it behind a semi-private space of private ownership? Is there one boundary or a transition space? Directness is a property whereby the interface is congruent with the property boundary and therefore adjacent to potential pedestrian flows; one enters/exits private space with little ceremony. The setback creates an interstitial space between public and private, it establishes distance through a doubling of boundaries. Crossing a setback, one is initiated into the private realm (typically via displays of one kind or another) without necessarily feeling that one is in the private realm.

Opaque/Transparent: Can one see clearly into private space from public space and vice versa? Transparency is important because it extends the public gaze from the street into private space, enabling commercial and social exchange. Gazes are exchanged between interior and exterior; products are projected into the public realm through window displays. By contrast, opacity removes any sense of ambiguity from boundary conditions, yet in so doing can bespeak the presence of a mystery or secret - entry signs and portals can suggest a private territory that is hidden.

Car/Pedestrian: Is the primary mode of access by car or foot? This variable is significant in understanding the ways in which public/private interfaces are transformed by the car-based city. Car access disconnects access from, and cuts across, pedestrian flows. The car/pedestrian variable aligns with the public/private axis to some degree in the sense that the car is a bubble of privacy within public space. Drivers are in traffic (rarely aware that they are traffic) while pedestrians are in the street. When the interface at either end of a trip is drive-out/drive-in then drivers remain sealed in private space. The car can be a means to bypass the public pedestrian network.

While these variables have a two/fold binary structure, each is a continuum with many degrees of accessibility, setback, opacity and car dependency. There are other salient variables we could include (sound penetration, underground/overground access, entry protocols) but they would all lead to unreadably complex typologies. While the interface is complex, a typology must limit the number of types to be usefully held in the mind. Psychologists have long suggested the limit is about seven (Miller 1956). Our goal, to quote Einstein, is to make the typology 'as simple as it can be, but not simpler'; or perhaps Whitehead: "Seek simplicity and distrust it". We are not, however, seeking to locate interface elements or essences, but rather to construct a framework through which to analyse complexities and ambiguities. The mapping of such properties requires shared methodological protocols for consistency. In our study access is established by the presence or absence of entry signage including names, numbers 
and mailboxes. We defined a setback as a semi-private entrance space that is open from the street and large enough for social exchange; if it is possible to knock on the door without leaving public space then we identified it as a direct interface. Transparency is based on the visual judgement that the private interior is part of the visual field of the passing pedestrian. The dominant mode of access is defined by whether or not one enters through a carpark.

Of the vast array of theoretically possible interface types we suggest five primary interface types that are diagrammed in both plan and section in Figure 1. Each interface type sets up different relations of access and visibility across the interface.

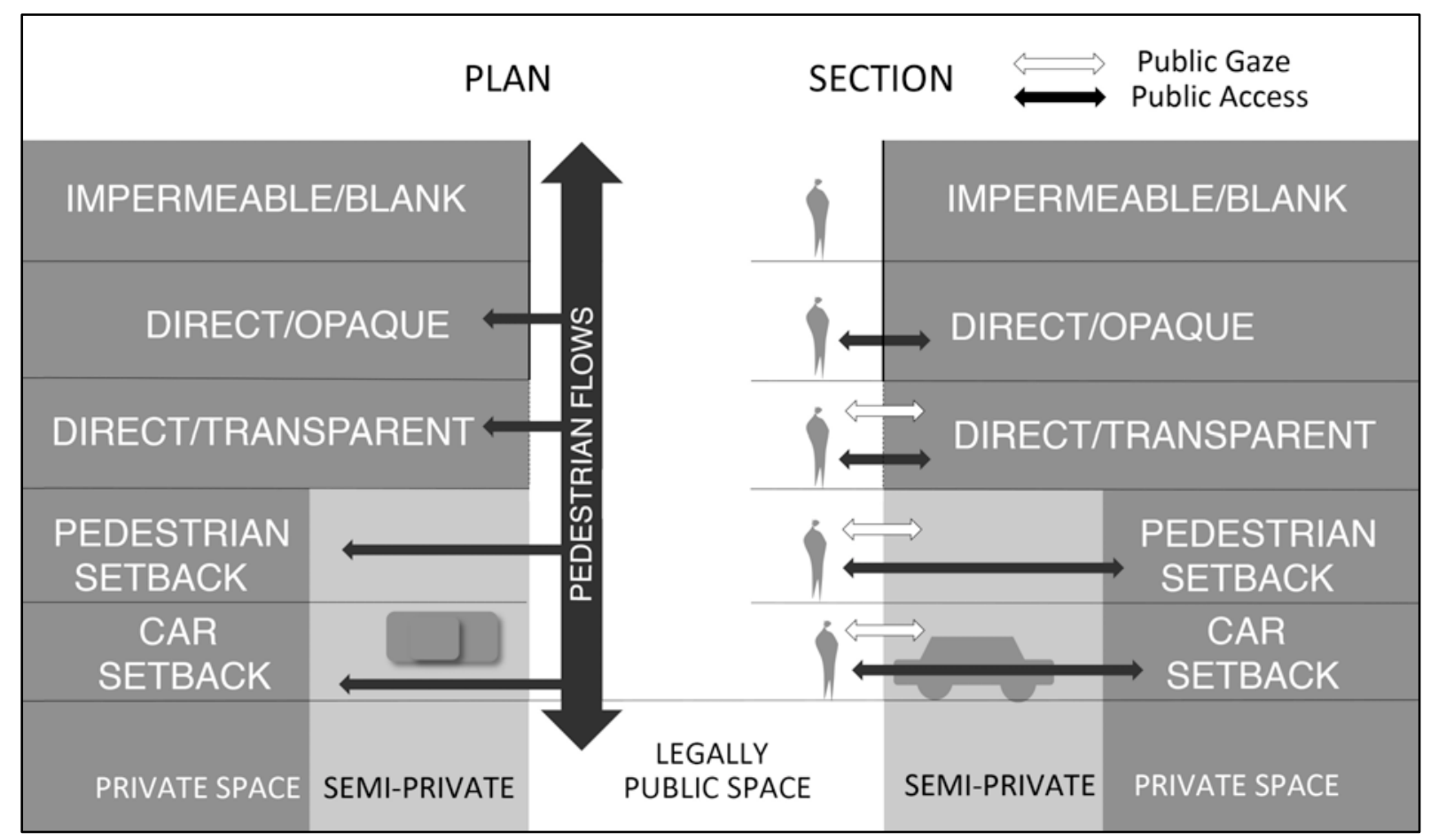

Figure 1: Five Interface Types

The first class of interfaces involves those that are impermeable to primary pedestrian access. This is the kind of interface that is widely regarded as inactive, not contributing to street-life and in some locations as a threat to public safety. For purposes of simplicity this type collapses several subtypes as illustrated in Figure 2A. Blank interfaces include blank walls, fencing or landscaping on the public/private boundary without transparency or pedestrian entry. This is the kind of interface produced by large lot development and on the sides and rear interfaces of many properties. It is common for industrial and commercial functions. Rear pedestrian entries are incorporated into this category unless they are identified with street numbers or signs. Typical examples would include the exterior of warehouses, malls, carparks and bigbox retailers. Some impermeable interfaces comprise garage doors or car entries directly on the street where only vehicles cross the boundary. While this may be a gate or void it is not a pedestrian entry and is socially blank. Other impermeable interfaces are transparent with private space clearly visible from public space but without access. Typical examples include showrooms and transparent fencing.

Direct interfaces incorporate those where pedestrians enter directly into private space from the street without an interstitial zone of semi-private space. The 'direct/opaque' type (Figure 2B) is common for residential apartments, industry and office where little social or commercial exchange takes place at the entrance. The 'direct/transparent' type (Figure 2C) incorporates a direct visual link into private space and tends to dominate shopping strips that rely on a direct/transparent display for passing trade. Such an interface may or may not be used for commercial functions and is rare for industry and residential. 


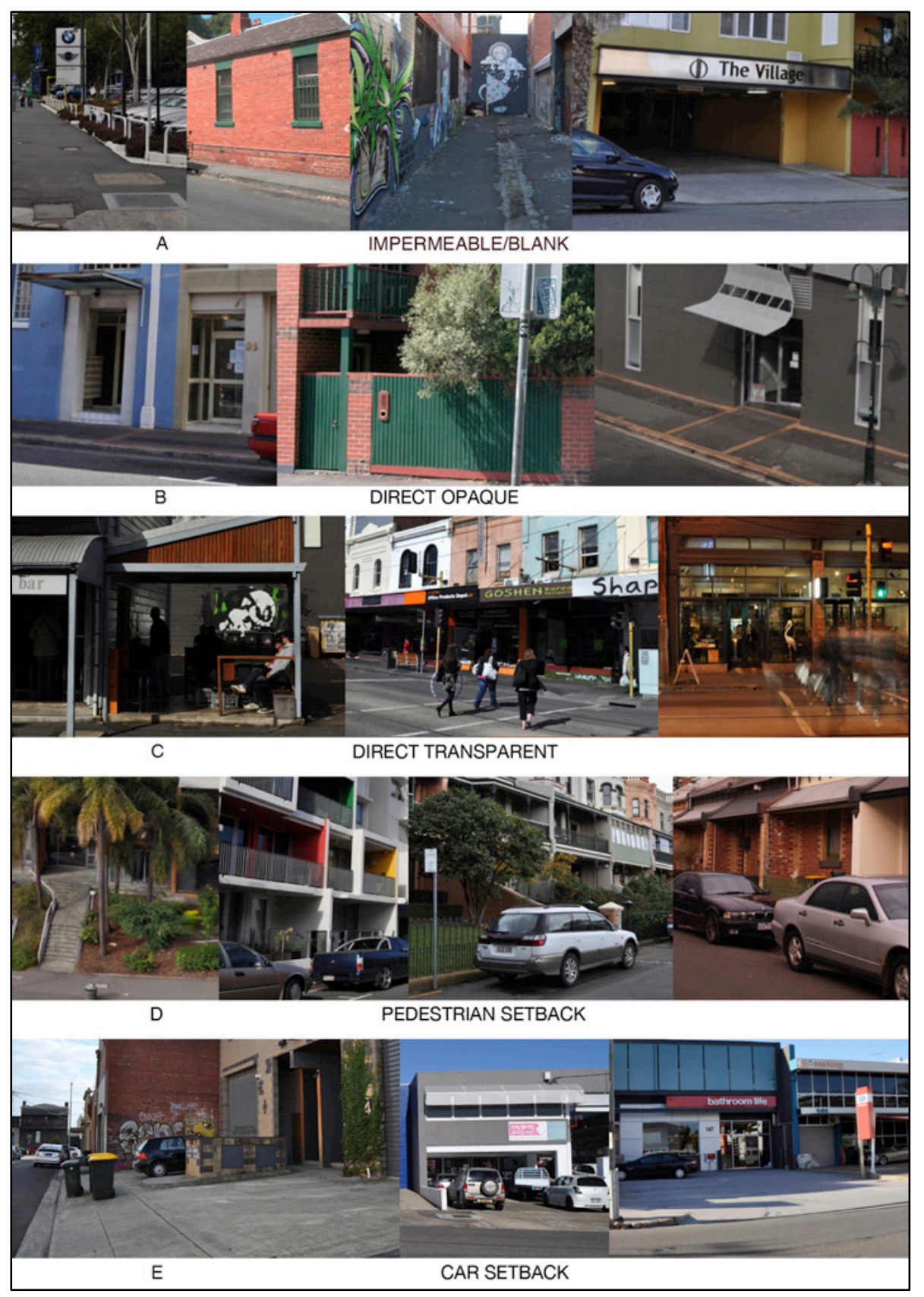

Figure 2: Examples of Interface Types

Setback interfaces indicate that access to private space first entails negotiating a zone of semi-private space before crossing a deeper interface into fully private space. The 'pedestrian/setback' type is where the entry is set back from the legal boundary behind a mediating pedestrian space (Figure 2D). This is the category that prevails in suburbia where the interstitial zone mediates social encounter and represents social identities. What we have termed the 'car/setback' is where the setback space is a carpark (Figure $2 \mathrm{E})$ and pedestrian flows are separated from the entrance by parking space.

While this five part typology can be easily elaborated into additional sub-categories (such as those incorporated under impermeable), we believe that it covers the gamut of possible interface types in a manner that is useful for mapping and analysis. Before we proceed, however, it is important to note that where the public/private interface gives access to multiple entities - whether houses, firms, apartments or shops - we find the emergence of secondary interface systems located well beyond the public private boundary as in a housing estate, office building or shopping mall. Any of the interface types outlined above may then be reproduced within a semi-public or quasi-public realm with types again geared to 
functions. While we have contained our study to the legal public/private boundary, we note that all secondary interface systems plug into the public network and they do so utilizing all of the types outlined above. Pedestrians may enter the shopping mall, housing project, apartment building or gated community through a direct or setback entry and in some cases such places may be impermeable to pedestrians (car/blank type).

One example of deploying such a typology in our study (Melbourne) is shown in Figure 3 where the direct/transparent interfaces of shopping strips (aqua) contrast with the pedestrian/setbacks (green) of the back streets and residential areas. The relatively distributed direct/opaque entries (orange) are mostly apartments and businesses. Car/setbacks (purple) show the dominance of cars in some streets while concentrations of impermeable facades (grey) generally indicate industry, large institutions or laneways.

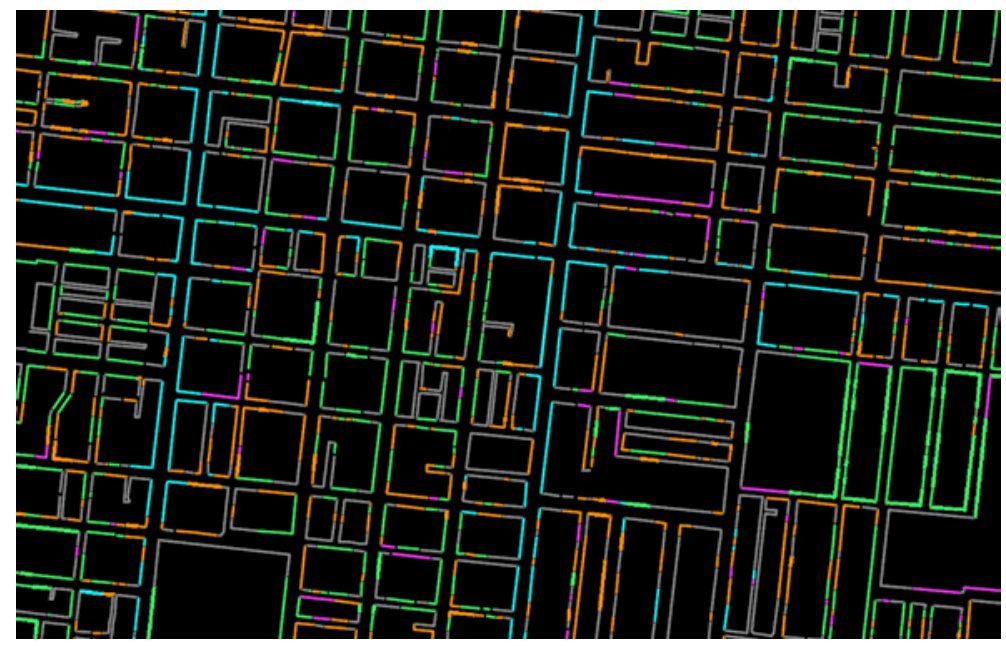

Figure 3: Interface Map, Fitzroy, Melbourne 2011

\section{COMPLEXITY \& ADAPTATION}

This typology is simply based on combinations of setback, transparency, access and mode of access, yet since each of these variables is a continuum there could be an almost infinite number of interface types. To extend the typology would produce a more nuanced system but any mapping of such categories would become progressively less readable and slippages between types would multiply. There are many variations that lie between the categories mapped here: semi-transparency (the high but somewhat open picket fence), semi-setbacks (limiting potential social exchange), ambiguous 'back' entries and the mixing of cars and pedestrians (garden/carpark). There are many other conditions where the ambiguity between types involves socio-spatial rhythms: shops with roller doors overnight; windows with curtains; a door or garage that becomes an after-hours entry. To diagram and map such variations would produce an unmanageable complexity, yet rather than eliminate such ambiguities from our concern we want to foreground them in a manner that reveals a latent dynamism, a potential for change and adaptation. For instance, if an interface is opaque glass then it would be classed as blank, when replacing the glass could render it transparent. A high front fence produces a direct/opaque interface even when it could be easily demolished to create a pedestrian or car/setback. It is this range of possible morphological transformations, from one type to another, which we now wish to foreground.

Theories of complex adaptive systems that incorporate ideas of emergence and self-organization can be useful in this context (Miller \& Page 2007; Walker \& Salt 2006, Gunderson \& Holling 2002). The detailed outcomes of a complex adaptive system cannot be determined in advance but rather 'emerge' from practices of adaptation and self-organisation (Johnson 2001). Over time a regime with certain characteristics emerges and settles down, perhaps reinforced by urban design codes. Some key properties of complex adaptive systems include the diversity and redundancy of different parts such that each performs a multiplicity of functions where no single part is crucial to success and the system can adapt by moving forms, functions and flows around. The tendency to maximize efficiency of the system - often 
the goal of formal planning - can lead to a loss of redundancy. As with assemblage theory, there is no easy way to define the 'system' as each property becomes an interactive part of each streetneighbourhood-city. While such theory is useful for understanding complexity and adaptation the term 'system' carries connotations of predictability and systematic control - the 'complex adaptive assemblage' is a more accurate and useful label for the interfaces we have analysed.

This account of adaptation takes us back to the variables with which we began: access, setback, transparency and mode of access. Changes to access occur when pedestrian access is created or blocked: new enterprises or houses may open through blank frontages as large grain functions devolve into smaller ones. Existing entries may be closed when plots become consolidated or premises are closed down. Rear entries and garages may become main entries. Such changes are driven by changing economic and social circumstances; increased pedestrian flows may open up new markets, changing functions and enterprizes may require new entry protocols and expressions of identity.

Setback adaptations occur when the effective boundary between public and private is moved: when a high opaque front fence is constructed in front of a setback the semi-public space is eliminated and the type is converted. This may be a response to traffic or a desire for privacy or security. Increased pedestrian flows on streets with setbacks can produce a market for shops with direct/transparent interfaces. When a shop appropriates the zone immediately adjacent in public space this moves the effective interface and converts the type to a pedestrian/setback. The elimination of 'no man's land' setbacks on housing estates as proposed by Newman (1972) and others often entail a conversion from setback to direct.

Changes of transparency are the easiest to effect and to reverse, often on a daily rhythm. Transparency is driven by different forms of production, reproduction, exchange and consumption. In general transparency is necessary for exchange (social and commercial) and consumption but can be a problem for production and domestic space. Adaptation between modes of access occurs when there is a shift between wheels and feet as the primary mode of entry across the legal public/private boundary; from drive-in/drive-out to pedestrian interface or vice versa. Increased traffic flows can lead to conversion of front entries and gardens to carparks, often driven by changes of function from residential to retail or commercial. Garage entries that are impermeable to pedestrians can be adapted into shopfronts either permanently or on an alternating car/pedestrian rhythm. Finally, there are forms of adaptation that link all of the interface types to secondary interface systems where multiple occupancies are accessed through the interface. This is an adaptation that moves the effective meet and greet functions of the entrance to a deeper level where a new interface system prevails. The adaptation from single to multiple occupancy may be driven by a conversion from warehouse to housing.

While there are many possible adaptations from one type to another, we now illustrate those most evident in our fieldwork. Figure 4 shows examples of adaptations of impermeable interfaces converted to direct or setback types. Figure $4 \mathrm{~A}$ is common - where a shop emerges from garage doors with a change of transparency and access. Figure 4B shows a former factory which becomes a car/setback for professional offices. Figure $4 \mathrm{C}$ is a café that emerged from a blank interface, creating a pedestrian/setback in a laneway. Figures $4 \mathrm{D} \& 4 \mathrm{~F}$ are examples of conversions of blank rear interfaces into public entrances for restaurant (D) or garage-top housing (F). Figure $4 \mathrm{E}$ convert a former rear entry to a car/setback. 


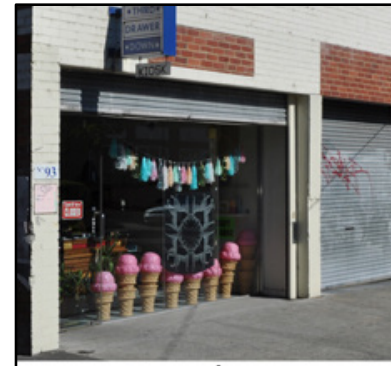

A

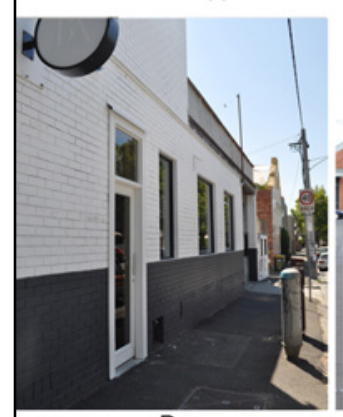

D

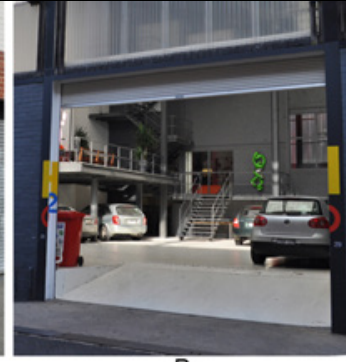

B

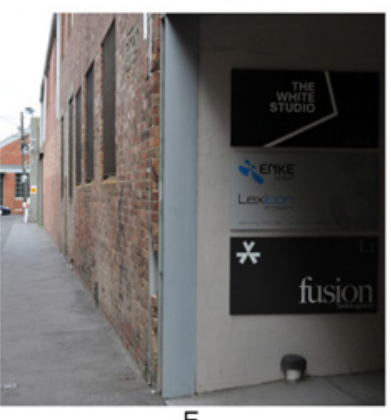

E

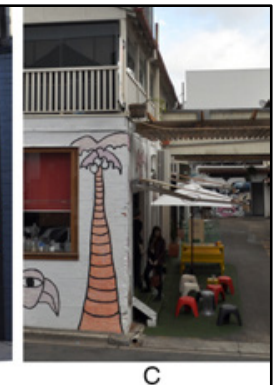

C

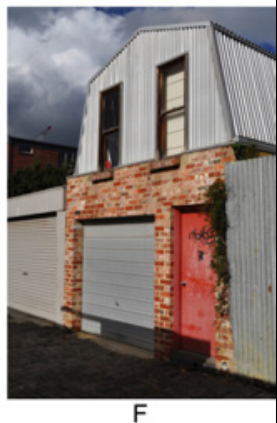

$\mathrm{F}$

Figure 4: Adaptations of Impermeable Interfaces

Figure 5 shows examples of adaptations of direct interfaces. Direct/transparent shopfronts are easily adaptable through change of transparency to nightclub (5A) and housing (5B), often linked to changes of economic cycle and pedestrian flow. The appropriation of public space for café tables immediately adjacent to a shopfront (Figure 5C) converts the interface type to pedestrian/setback as it moves the effective interface forward. Figure 5D shows a formerly direct/opaque entry adapted to a secondary interface system as a former industrial shell is adapted to house the small grain sublets of a market.

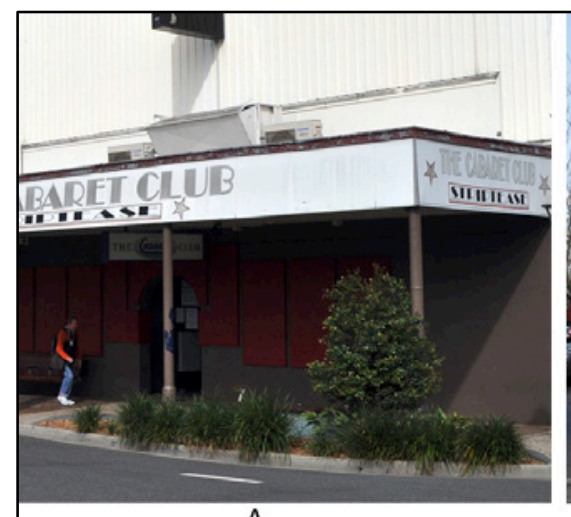

A

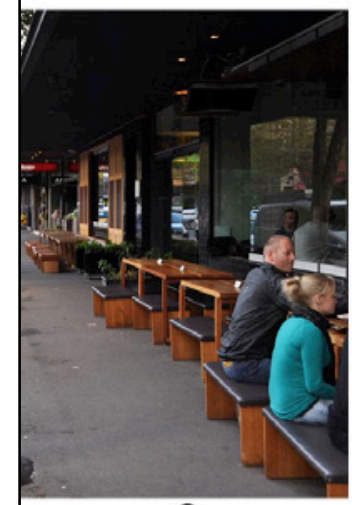

C

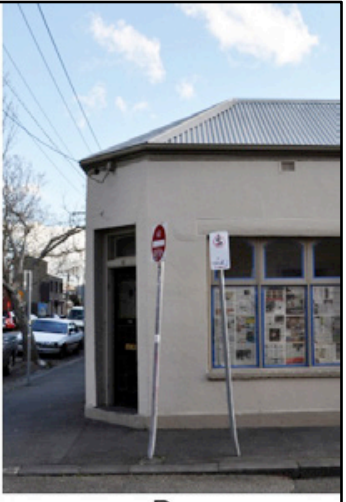

B

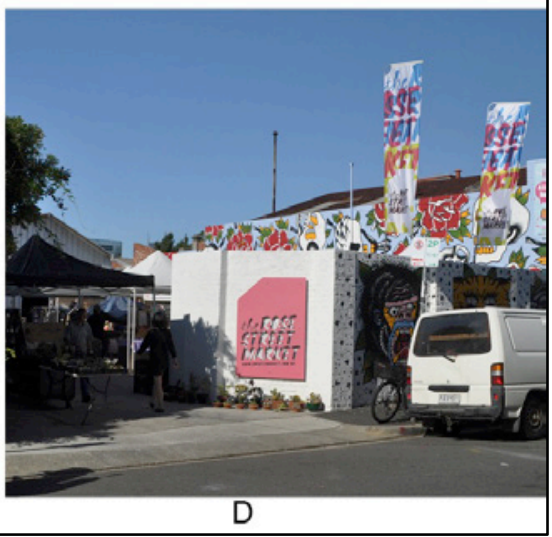

D

Figure 5: Adaptations of Direct Interfaces 
Figure 6 shows adaptations of interfaces: a cafe (6A) emerges from a garage converting car/setback to pedestrian/setback. There are examples where the front garden becomes a shop (6B) and many where the pedestrian/setback becomes direct/opaque (6C). Figure $6 \mathrm{D}$ is a brothel where the front entry has been closed - effectively converting the interface to blank/impermeable with a more 'private' public entry to the rear.

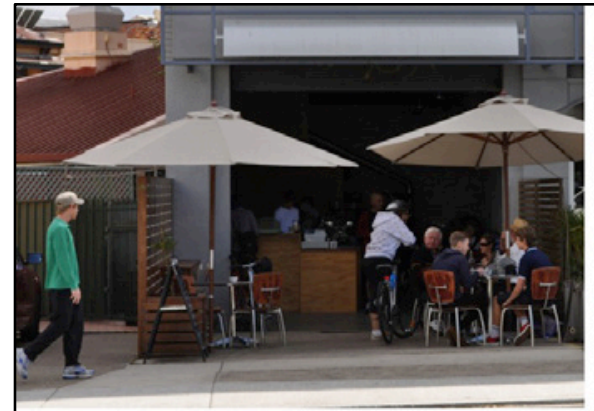

A

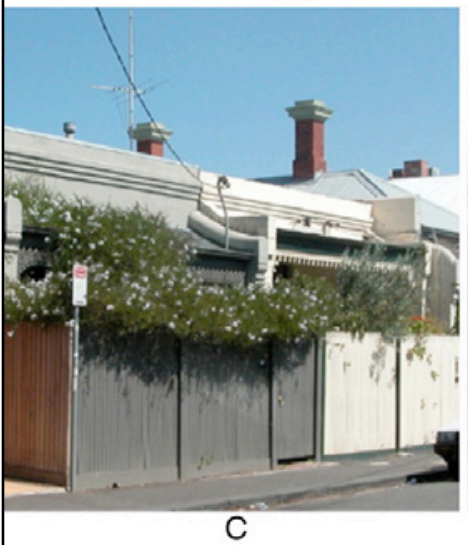

C

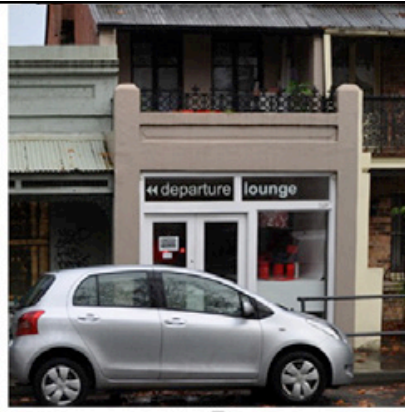

B

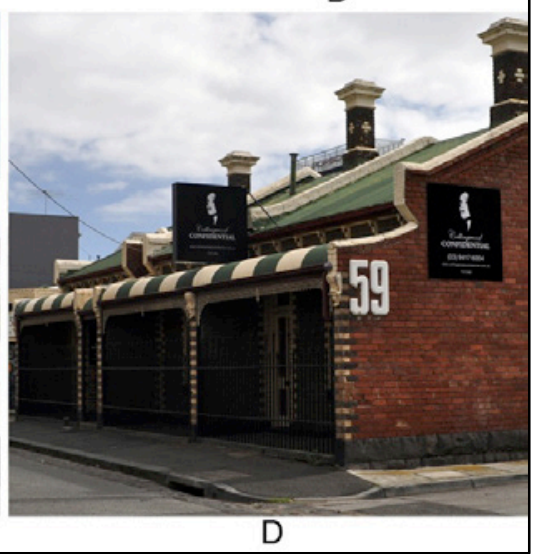

Figure 6: Adaptations of Setback Interfaces

Some of these transformations are effected on a daily rhythm as screens, gates, doors and blinds are opened and closed, furniture and loose parts are rearranged. There are also seasonal rhythms as sidewalk dining comes and goes. Other adaptations require construction and become more permanent. Some require formal planning approval while others do not; some may involve informal changes of function that are not strictly legal - such as living in shops or operating shops from warehouses. We are not suggesting that this is a full range of interface adaptations - Figure 7 is a diagram of those we have illustrated within this 5-part typology to show some of the connections. Notice that figures 4C and 6D appear as conversions between the same types but this is no simple reversal - the blank factory wall becomes a pedestrian/setback on the one hand while the residential setback becomes a blank-fronted brothel on the other. Likewise building a shop in the front garden (6B) is not a reversal of alfresco dining (5C) even though there is a typological reversal. In our fieldwork some types appear to be more adaptable than others; a high proportion of adaptations originate from impermeable conditions and very few from car/setbacks. 


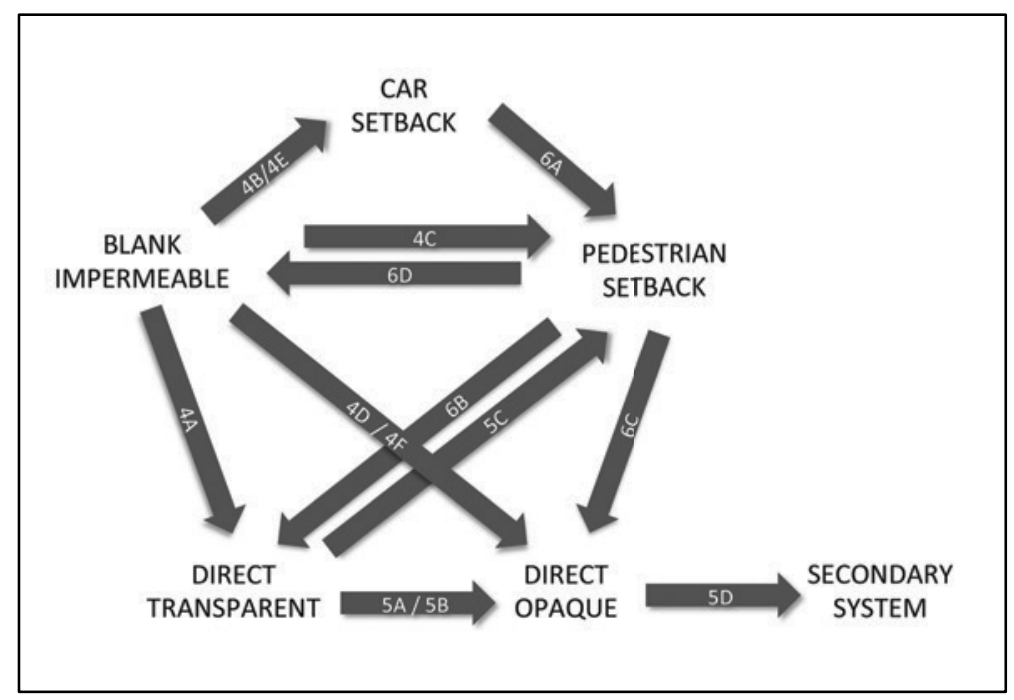

Figure 7: Adaptations of Interface Types

\section{DISCUSSION}

Thus far we have identified and mapped a set of interface types and then explored the ways in which some of these types are adapted to become others; we have progressed from a seemingly static typology to a set of more dynamic transformations. But what is at stake in all this, why might it matter? The public/private interface has long been a highly salient urban design issue in a broad range of key urban design theories from Jacobs, Alexander, Lynch and Newman through to Gehl and the present. Current urban design research, whether on placemaking, codes or creative clusters, continues to raise the interface as a salient issue. The twofold variables used to generate our types (access, setback, transparency, car-dependency) are rooted in the earlier literature. Each of them is characterised by a logic of moving between poles of a continuum, by the enabling and constraining of connections between public and private space. These variables are the basis for our interface types, four of which are intersections of two variables (direct/transparent, direct/opaque, car/setback, pedestrian/setback) plus the impermeable/blank type. Each of these can be subdivided and further variables can be added but the cost in understanding is high. Typologies emerge in response to the need to filter the complexity of the city through a language of form, as tools for both urban design analysis and control. Our need for a typology emerged from a desire to compare interface mapping with other forms of mapping that have long become stock in trade for urban design analysis such as grain size, density, building type, permeability and function.

A word is in order about the epistemology and ontology of these interface types. The types are not archetypes, they are concepts, diagrams and tools for thinking rather than eternal or underlying truths. The types are the result of much mapping, experimenting and sifting but they are not settled. Typologies are reductive by definition; they reduce the complexity of the interface to an abstraction. These are not ideal types and the constructed interfaces are not copies of them. The types are typical formal patterns that are immanent to the urban assemblage and are productive of it.

It is the ambivalence of the interface - its twofold nature as a mediator of public/private space - that makes assemblage theory a useful framework for investigation here. Assemblage thinking takes an ontology of flows, of connections/divisions, of betweenness, as its primary subject. Within this framework each of the interface types can be construed as a 'diagram' (in assemblage jargon an 'abstract machine' Deleuze \& Guattari 1987: 141) embodying the immanent and productive forces of an assemblage. A key source in this regard was Foucault's concept of the panopticon - the socio-spatial diagram of asymmetric visibility that is productive of subjectivity within disciplinary regimes of power (Foucault 1979; Deleuze 2007: 123). However, within Deleuze \& Guattari's conception micro-spatial practices of power can also be liberating. The interface types are micro-practices of power; they provide or prohibit access and the penetrations of the public gaze; they enable and constrain privacy and publicity. Interface assemblages work to produce wealth, ideas, identities and subjectivities. These forms 
of social and economic production and reproduction are key drivers of both the types and their adaptations. Just as Lefebvre (1991: 26) long ago pointed out the recursive condition of urban space as both a means of production and a product, the interface types are at once products of urban design and modes of social and economic production and exchange. While we have presented different diagrams for each of these interface types, a generic diagram of a flow of public life at a tangent to a private territory underlies them all. This pattern prevails with variations of accessibility, privacy, security and sociality because it is productive of economic exchange and of social identity and subjectivity.

This study emerged from an investigation of why it is that creative clusters emerge within some kinds of urban morphology rather than others. While there is not scope to pursue this here, our provisional response is linked to both diversity and adaptation. Interface adaptations are an important mode of innovation in urban design where an underlying potential becomes actualized; new connections are formed between production, exchange and consumption; new forms of urban intensification become possible with a greater utilization of urban space. This is, however, a very complex issue - creative industries are also attracted to ex-industrial buildings, density, heritage, central locations, cheap rents, loose regulatory regimes and other factors (Evans 2009; Bell \& Jayne 2004; Brown \& Meczynskivan 2009; van Heur 2009). It may be argued that our typology reflects a bias towards the particular kind of urban fabric we have studied - the Australian inner-city. This is a diverse urban fabric with a much larger range of interfaces than is likely to be found in most urban districts; this makes it a useful window onto the larger question of interface typologies and adaptations. The suburb, shopping strip, central city and so on generally have a much more homogenous interface typology and mapping them is easy.

A crucial issue here is the degree to which interface types are geared to functional types and the ways that codes that enforce uniformity of one often tend to reinforce uniformity of the other. Residential properties are primarily geared to pedestrian/setback and direct/opaque interfaces at different densities; small grain retail is highly dependent on the direct/transparent interface; small grain industry and commerce are often geared to direct/opaque and car/setbacks. Manufacturing is linked to direct/opaque and blank/impermeable interfaces. These gearings, however, are also mediated by grain-size because large-grain functions of any kind (factories, carparks, retail) tend to produce blank/impermeable interfaces. High levels of car-dependency will tend to produce blank facades or car/setbacks. One reason for taking the potential adaptation of impermeable interfaces seriously is that a concentration of cardependent interfaces can generate the syndrome of density without intensity (Author 2013). As we move towards a low-carbon city and car-dependency declines, parking spaces adjacent to major pedestrian flows will become available for adaptation and transformation.

Our focus on the legal public/private boundary has led us to identify what we call secondary interface systems including the quasi-public spaces of shopping malls, corporate environments, apartment buildings and housing enclaves. These systems can be accessed via any of the five main interface types including car-dependent entries that are impermeable to pedestrians. A key reason why these interface systems should be treated separately is that they fall under private codes - the collective private governance of an institution, shopping mall or body corporate. In such cases the scope for interface adaptability will be different - the shop within the shopping mall and the house within the enclave are generally subject to strict functional mix formulae and private covenants respectively. The issue of privatization, however, is not simple because there is also scope for secondary interface systems to become more flexible than public controls.

Urban design codes have long incorporated provision for active edges and eradication of blank interfaces, however, the question of relating interface types to regulations remains a key area for research. While we see interface adaptation as a productive form of innovation that requires flexible codes, there is also often a case for interface consistency. This is a conundrum rather than an answer one way or the other. To recognize the nature and importance of interface adaptation is not necessarily to endorse deregulated controls. Design codes that establish consistency of interface can sustain highly valued and productive urban streetscapes. Some interfaces do not work when mixed - retail synergies rely on a consistency of direct/transparent interfaces - hence the eradication of blank, setback and carbased interfaces from the private shopping mall. Nor are we suggesting that all interface adaptations are productive or innovative - many are linked to dereliction and to a more car dependent city. On the other 
hand it is important to acknowledge that the enforcement of interface type limits both the diversity of interface flows within that zone and the potential for adaptation. This is a conundrum for urban design, indeed part of a much larger conundrum about what forms of urban regulation best enable the emergence of diversity (Author 2009).

The interface typology we have presented is a tool for mapping and analysing one dimension of how the city works and the ways it might be managed and transformed. The interfaces cannot be considered apart from the larger set of issues that comprise the urban assemblage - the mixes and intersections of grainsizes, functions, densities, building ages and heights that was first explored by Jacobs over 50 years ago. Jacobs was the mother of all urban assemblage thinkers who articulated so many of the ways that cities work - the interconnections, synergies, alliances and rhythms that underlie the emergence of diverse and productive urbanity. The interface was celebrated by Jacobs in terms of 'eyes on the street', the creative use of sidewalks and stoops and the aesthetic of the 'place ballet'. Yet this is also the dimension of her work that has been least developed. The mapping of functions, permeability/walkability, grain size and density together with analysis of their interrelations are now stock in trade for urban design discourses; we suggest that interfaces can be usefully added to this list.

\section{REFERENCES}

Alexander C, et al 1977 A Pattern Language (Oxford University Press, Oxford)

Altman I, 1975 The Environment and Social Behaviour (Brooks Cole, Monterey)

Bauman Z, 1993 Postmodern Ethics, Blackwell, Oxford.

Bell D, Jayne M (eds), 2004 City of Quarters (Ashgate, Aldershot)

Benjamin W, 1978 Reflections (Harcourt, Brace \& Jovanovich, New York)

Bentley I, Alcock A, McGlynn S, Smith G, Murrain P, 1985 Responsive Environments (Architectural Press, London)

Brown J, Meczynski M, 2009 "Complexcities: Locational Choices of Creative Knowledge Workers" Built Environment, 35(2) 238-52

Carmona M, Heath M, Oc T, Tiesdell S, 2003 Public Places, Urban Spaces (Architectural Press, London)

Carmona M, 2010 "Contemporary Public Space, Part Two: Classification" Journal of Urban Design 15(2) 157-73

Corner J, 1999 "The Agency of Mapping", in Mappings Ed D Cosgrove (Reaktion, London) pp 213-52

Delanda M, 2006 A New Philosophy of Society: Assemblage Theory and Social Complexity (Continuum, New York)

Deleuze G, Guattari F 1987 A Thousand Plateaus: Capitalism and Schizophrenia (University of Minnesota Press, Minneapolis)

Deleuze G, 2007 Two Regimes of Madness (Semiotext(e), New York)

Evans G, 2009 "Creative Cities, Creative Spaces and Urban Policy" Urban Studies 46(5/6) 1003-40.

Farias I, Bender T, (eds) 2010 Urban Assemblages (Routledge, London)

Ford L, 2000 The Spaces Between Buildings (John Hopkins University Press, London)

Foucault M, 1979 Discipline and Punish: The Birth of the Prison (Vintage, New York)

Gehl J, Johansen L, Reigstad S, 2006 "Close encounters with buildings" Urban Design International 11 $29-47$.

Gehl J, 1987 Life Between Buildings (Van Nostrand Reinhold, New York)

Gehl J, Gemzoe, L, 1996 Public Spaces and Public Life (Danish Architectural Press, Copenhagen)

Goffman I, 1959 The Presentation of Self in Everyday Life (Penguin, Harmondsworth)

Gunderson L, Holling C, (eds) 2002 Panarchy (Island Press, Washington)

Habraken J, 1998 The Structure of the Ordinary (MIT Press, Cambridge, Ma.)

Iveson K. 2006 "Strangers in the Cosmopolis" In: Cosmopolitan Urbanism Ed J. Binnie, S. Millington \& C. Young (Routledge, London) pp. 70-86.

Jacobs J, 1961 The Death and Life of Great American Cities (Vintage, New York)

Johnson S, 2001 Emergence: The connected lives of ants, brains, cities and software (Penguin, London)

Latour B, 1987 Science in Action (Harvard University Press, Cambridge, Ma.)

Lefebvre H, 1991 The Production of Space (Blackwell, Oxford)

Lynch K, 1981 A Theory of Good City Form (MIT Press, Cambridge, Ma.)

Madanipour A, 2003 Public and Private Spaces of the City (Routledge, London)

McFarlane C, 2011 "Assemblage and Critical Urbanism" City 15(2) 204-224 
Mehta V, 2007 "Lively Streets" Journal of Planning Education and Research 27 165-187.

Miller, G. (1956). "The magical number seven, plus or minus two: Some limits on our capacity for processing information" Psychological Review 63 (2) 81-97.

Miller J, Page S, 2007 Complex Adaptive Systems (Princeton University Press: Princeton)

Moudon, A, (1994) "Getting to Know the Built Landscape" In: Ordering Space Ed K. Franck \& L. Schneekloth (Van Nostrand Reinhard, New York) pp. 289-311.

Newman O, 1972 Defensible Space (Macmillan, New York).

Simmel G, 1950 "The Stranger", in The Sociology of Georg Simmel Ed K Wolff, (Free Press, New York) pp 402-408

Simmel G, 1978 The Philosophy of Money (Routledge, London)

Simmel, G, 1997 "Bridge and Door" in Rethinking Architecture Ed N. Leach (London: Routledge).

Sorkin M, 1992 Variations on a Theme Park (Hill \& Wang, New York)

van Heur B, 2009 "The Clustering of Creative Networks" Urban Studies 46(8) 1531-52

Walker B, Salt D, 2006 Resilience Thinking (Island Press, Washington) 